\title{
Hemșirelik öğrencilerine lisans eğitimi sırasında verilen meme kanserine yönelik eğitimin bilgi ve tutuma etkisinin incelenmesi
}

\author{
Investigation of the effects of breast cancer education given to nursing \\ students during undergraduate education on knowledge and attitudes
}

Figen Erol Ursavaș®

\section{öz}

AMAÇ: Hemşirelik Bölümü’nde öğrenim gören öğrencilerin lisans eğitimi sırasında meme kanserine yönelik aldıkları eğitimin bilgi ve tutumları üzerindeki etkilerini incelemektir.

GEREC ve YÖNTEMLER: Tanımlayıcı ve kesitsel tipte yapılmıştır. Araştırmanın örneklemini iç Anadolu'da bulunan bir üniversitenin hemşirelik bölümünde okuyan 2, 3 ve 4. Sınıfta okuyan 170 öğrenci olușturmuștur. Veriler Google Forms ile Nisan-Mayıs 2020 tarihinde toplanmıştır. Veriler, sayı, yüzde, ortalama, standart sapma, ki kare ve bağımsız gruplarda Anova testi ile analiz edilmiştir.

BULGULAR: Öğrencilerin \%100 kendi kendine meme muayenesi (KKMM) hakkında bilgi sahibi olduğunu, kadın öğrencilerin \%81,9'nun KKMM yaptığı, \%24,4'nün her ay düzenli olarak yaptığı belirlenmiştir. Öğrencilerin \%37,1'inin annesinin KKMM yaptığı, \%47,6'sının annesinin daha önce mamografi çektirmediği saptanmıştır. Sınıflara göre öğrencilerin, meme kanseri risk faktörleri ve erken tanı yöntemleri bilgi düzeyi toplam puan ortalamalarında sınıflar arasında istatistiksel olarak önemli bir fark olduğu belirlenmiştir.

SONUC̦: Hemşirelik öğrencilerinin meme kanserine yönelik tutumlarının geliştirilmesi gerektiği saptanmıştır.

Anahtar Kelimeler: Bilgi, kendi kendine meme muayenesi, meme kanseri, risk faktörü, tutum

Bu çalışma 18-19 Aralık 2020'de düzenlenen 2. Uluslararası, 3. Ulusal Onkoloji Hemşireliği Kongresinde sözel bildiri olarak sunulmuștur.

Çankırı Karatekin Üniversitesi Sağıı Bilimleri Fakültesi, Hemşirelik Bölümü, Çankırı, Türkiye

Yazışma Adresi/ Correspondence:

Dr. Öğr. Üyesi Figen Erol Ursavaş

Çankırı Karatekin Üniversitesi Sağıık Bilimleri Fakültesi, Hemşirelik Bölümü, Çankırı, Türkiye

Tel: $\quad$ +903762131702

E-mail: figenerolll@gmail.com

Gelis/ Received: $\quad 18.01 .2021$

Kabul/ Accepted: $\quad 21.02 .2021$

\section{ABSTRACT}

OBJECTIVE: The aim of this study is to examine the effects of the education nursing students have received on breast cancer during their undergraduate study on their knowledge and attitudes.

MATERIAL and METHODS: This study was conducted descriptive and cross-sectional design. The sample of the study consisted of 170 2nd, 3rd- and 4th-year students studying in the nursing department of a university located in Central Anatolia. The data were collected via Google Forms between April and May 2020. The data were analyzed by number, percentage, mean, standard deviation, chi square and Anova test in independent groups.

RESULTS: It was determined that $100 \%$ of the students had breast self-examination (BSE), $81.9 \%$ of female students had BSE and $24.4 \%$ regularly did it every month. It was determined that mothers of $37.1 \%$ of the students had BSE and mothers of $47.6 \%$ had not had a mammography before. There was a statistically significant difference between total mean scores of the students for knowledge level of breast cancer risk factors and early diagnosis methods in terms of the grades.

CONCLUSION: It was found that attitudes of nursing students toward breast cancer should be improved.

Keywords: Knowledge, breast self-examination, breast cancer, risk factor, attitude

\section{Gíriș}

Meme kanseri ülkemizde kadınlar arasında en sık görülen kanser türü olup, insidansı yüzbinde 43,0 'dür. ${ }^{[1]}$ Dünyada ise kadınlar arasında görülme insidansı yüzbinde 46,3 olarak saptanmıştır. ${ }^{[2]}$ Hemşireler meme kanseri ile ilgili korkuları gidermek, bilgiyi arttırmak, yanlıs algılamaları düzeltmek ve olumlu tutumları geliştirmek için kilit bir konumdadır. ${ }^{[3]}$ Sağlık ekibi içerisinde hastalarla en çok zaman geçiren ve eğitici, danışmanlık rolleri ile hasta bakımına yön veren hemşirelerin, meme kanseri ve erken tanıya yönelik bilgi düzeylerinin yeterli olması önemlidir. ${ }^{[4]}$ 
Amerikan Kanser Birliği (AKB), meme kanserine neden olan birçok risk faktörü tanımlamakta ve erken tanının önemi vurgulanmaktadır. Meme kanserinin erken teşhisi ile mortalite oranının önemli ölçüde azalacağı belirtilmektedir. ${ }^{[5]} \mathrm{Bu}$ nedenle hemşirelerin meme kanserine yönelik eğitim ve danışmanlık rollerini yerine getirebilmesinde, meme kanseri risk faktörleri ve erken tanı yöntemleri hakkında bilgi sahibi olması önemlidir.

Çalıştıkları ortamlar nedeniyle hemşireler meme kanserine yönelik bilgiyi arttırmak, korkuları ortadan kaldırmak, meme kanseri hakkındaki yanlış algılamaları düzeltmek ve meme sağlığı davranışlarının benimsenmesini teşvik etmek için anahtar konumdadırlar. Ancak hemşirelerin rollerini yeterli olarak yerine getirebilmeleri kendi bilgilerine ve tutumlarına bağlıdır. ${ }^{[3]}$ Hemşirelik öğrencilerini, hemşire olarak çalışmaya başlamadan önce hastalara yeterli bakım sağlayabilmeleri için, yeterli düzeyde bilgi kazandırmak, olumlu tutumlar geliştirmek hemşire eğitimcilerin sorumluluğundadır.

Hemşirelik öğrencilerinin lisans eğitiminde temel meme kanseri ve erken tanıya yönelik bilgi eksikliği, mezun olduktan sonra hemşirelerin danışmanlık ve eğitim rollerini yerine getirirken zorluk yaşamalarına neden olabilir. Bu nedenle hemşirelik öğrencilerinin meme kanserine yönelik bilgi ve tutumlarının incelenmesi önemlidir. Literatürde hemşirelik öğrencilerinin kendi kendine meme muayenesi yapma durumlarının ve bilgisinin sorgulandığı, birçok çalışma olmasına rağmen, ${ }^{[6-9]}$ Meme kanserine yönelik risk faktörleri hakkında bilgi düzeyinin incelendiği sınırlı sayıda çalışmaya ulaşılmıştır. ${ }^{[10,11]} \mathrm{Bu}$ çalışmanın ülkemizde hemşirelik öğrencilerinin tüm meme kanseri risk faktörleri (yaşam tarzı ile ilgili risk faktörleri, değiştirilemeyen risk faktörleri, etkileri belirsiz risk faktörleri, kanıtlanmamış veya tartışmalı risk faktörleri) hakkındaki bilgi düzeyini değerlendiren ilk çalışma olması öngörülmektedir.

Hemşirelik öğrencilerinin mevcut risk faktörlerinin farkında olması ve önlenebilir (yaşam tarzı ile ilişkili risk faktörleri) risk faktörlerine hasta eğitimlerinde yer vermeleri hemşirelik bakımının geliştirilmesi, farkındalığın sağlanması için önemlidir. Ayrıca erken tanı yöntemlerini ve yaş aralıklarını bilmeleri hastaları doğru bir şekilde yönlendirmeleri ve danışmanlık rollerini yerine getirebilmeleri açısından da önem taşımaktadır. Bu bilgiler doğrultusunda çalışmanın amac1, hemşirelik bölümünde okuyan öğrencilerin lisans eğitimi sırasında aldıkları meme kanserine yönelik eğitimin bilgi ve tutumlarına etkisinin incelenmesidir. Çalışma sonuçlarının, hemşirelik lisans eğitimine katkı sağlayacağı ve gelecek çalışmalara yol göstereceği düşünülmektedir.

\section{GEREÇ ve YÖNTEMLER}

\section{Araștırmanın Tasarımı}

$\mathrm{Bu}$ araştırma tanımlayıcı ve kesitsel bir çalışmadır.

\section{Araștırmanın Evren ve Örneklemi}

Araştırma, İç Anadolu'da bulunan bir üniversitenin sağlık bilimleri fakültesi hemşirelik bölümünde yapılmıştır. Araştırmanın evrenini 2019-2020 öğretim yılı bahar döneminde 2, 3 ve 4 . Sinıfta okuyan hemşirelik öğrencileri $(\mathrm{N}=264)$ oluşturmuştur. Araştırmanın örneklemini ise Nisan 2020 - Mayıs 2020 tarihleri arasında çalışmaya katılmayı kabul eden n=170 öğrenci oluşturmuştur. Covid-19 pandemisi nedeniyle veriler Google Forms ile toplanmıştır.

\section{Örnekleme dabil edilme ölçütleri}

\section{- Hemşirelik 2, 3 ya da 4. Sınıf öğrencisi olmak}

- Araştırmaya gönüllü olarak katılmayı kabul etmek

Çalışmanın yapıldığı hemşirelik bölümünde, müfredatta meme kanseri ve KKMM'ye yönelik eğitim 2. sınıfta cerrahi hastalıkları hemşireliğinde verilmektedir. Diğer sınıflarda KKMM'nin nasıl yapıldı̆̆ına yönelik bir eğitim verilmemektedir. Fakat 4. sınıf halk sağlığı hemşireliği dersinde tarama programları kapsamında sıklığı anlatılmaktadır. Bundan dolayı 2, 3 ve 4. sınıf öğrencileri örnekleme dahil edilmiştir. Tüm öğrenciler meme kanserine yönelik eğitimi pandemi öncesi sınıf ortamında almışlardır.

\section{Verilerin Toplanması}

Araştırmanın verileri, sosyodemografik özellikler formu, Erken Tanıya Yönelik Tutum Formu, Meme Kanseri Risk Faktörleri Bilgi Formu ve Meme Erken Tanı Yöntemleri Bilgi Formu ile toplanmıştır. Veri toplama formu araştırmacı tarafından literatür taranarak oluşturulmuştur. ${ }^{[5,9,12,13]}$

Sosyodemografik Özellikler Formu: Yaş, cinsiyet, sınıf, ailede meme kanseri öyküsünü içeren 4 sorudan oluşmaktadır.

Erken Tanıya Yönelik Tutum Formu; Kendi Kendine Meme Muayenesi (KKMM)'ye yönelik bilgi, yapma durumu, yapma sıklığı, Annenin KKMM yapma durumu, Annenin daha önce mammografi çektirme durumu ve Anneye daha önce meme kanseri ve tanılama yöntemleri hakkında bilgi verme durumunu içeren 6 sorudan oluşmaktadır. ${ }^{[9,14]}$

Meme Kanseri Risk Faktörleri Bilgi Formu; Bu form AKB 2020 güncel bilgileri doğrultusunda hazırlanmıştır. Yaşam tarzı ile ilgili risk faktörleri (alkol kullanımı, fazla kilolu yada obez olma, fiziksel aktivite, çocuk sahibi olma, emzirme, doğum kontrol yöntemleri, menapoz sonrası hormon replasman tedavisi, meme implantları), değiştirilemeyen risk faktörleri (kadın olmak, ileri yaş, gen mutasyonu, ailede meme kanseri öyküsü, kişinin meme kanseri öyküsü, uzun olmak, dens meme yapısı, bening meme hastalıkları, erken menarş, geç menapoz, göğüs bölgesine radyoterapi alınması), etkileri 
belirsiz risk faktörleri (diyet ve vitaminler, çevredeki kimyasallar, sigara kullanımı, gece çalışması), kanıtlanmamış veya tartışmalı risk faktörlerini (antiperspiarntlar, sütyen kullanımi, kürtaj) içeren 26 sorudan oluşmaktadır. ${ }^{[5]}$ Formda doğru cevaplar 1 puan yanlış cevaplar 0 puan ile değerlendirilmiştir. Form literatür doğrultusunda araştırmacı tarafından hazırlanmıştır. Soruların anlaşılırlığı ve uygunluğunun değerlendirilmesi için uzman görüşü alınmıştır.

Meme Kanseri Erken Tanı Yöntemleri Bilgi Formu; KKMM başlama zamanı ve yapma sıklı̆̆ı, Klinik meme muayenesi başlama zamanı ve yapma sıklığı ve mammografi çektirmeye başlama zamanı ve sıklığını içeren 3 sorudan oluşmaktadır. ${ }^{[13]}$ Formda doğru cevaplar 1 puan yanlış cevaplar ise 0 puan ile değerlendirilmiştir. Form literatür doğrultusunda araştırmacı tarafindan hazırlanmıştır. Soruların anlaşılırlığı ve uygunluğunun değerlendirilmesi için uzman görüşü alınmıştır.

\section{Etik Onay}

Araştırmanın yapılabilmesi için, araştırmanın gerçekleştirildiği Çankırı Karatekin Üniversitenin Girişimsel olmayan etik kurulundan etik kurul izni (2020/165) alınmıstır. Öğrencilere e-posta yolu ve cep telefonlarına mesaj yolu ile anket formu linki gönderilerek çalışmanın amacı açıklanmış ve çalışmaya katılımın gönüllülük esasına dayalı olduğu bilgisi verilmiştir.

\section{İstatistiksel Analiz}

Araştırmadan elde edilen verilerin analizi, bilgisayar ortamında IBM SPSS Statistics for Windows version 22.0 (IBM Corp., Armonk, NY) kullanılarak yapılmıştır. Verilerin normal dağılıma uygunluğunun değerlendirilmesinde Skewness ve Kurtosis sonuçları kullanılmıştır. Veriler normal dağılım gösterdiği için parametrik testler kullanılmıştır. Veriler, sayı, yüzde, ortalama, standart sapma, ki kare ve Bağımsız gruplarda anova testi ile analiz edilmiştir.

\section{BULGULAR}

Araştırmaya katılan öğrencilerin yaş ortalaması

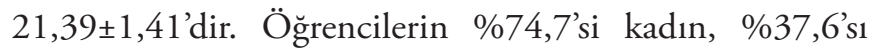
2. sınıf öğrencisi ve $\% 95,3$ ünün ailesinde meme kanseri öyküsü yoktur. Öğrencilerin \%100 KKMM hakkında bilgi sahibi olduğunu, kadın öğrencilerin \%81,9'unun yaptığı, \%24,5'inin her ay düzenli yaptığı belirlenmiştir. Öğrencilerin \%37,0'ının annesinin KKMM yaptığı, \%47,6'sının annesinin daha önce mammografi çektirmediği, \%61,8'inin annesine meme kanseri ve erken tanılama yöntemleri hakkında bilgi verdiği saptanmıştır (Tablo 1).
Çalışmaya katılan hemşirelerin cinsiyet faktörüne KKMM yapma durumları karşılaştırıldığında iki grup arasında istatistiksel olarak anlamı bir fark olduğu görülmüştür (Tablo 2).

Tablo 1. Hemşirelik öğrencilerinin sosyodemografik özellikleri ve erken tanıya yönelik tutumları

\begin{tabular}{|c|c|c|}
\hline Değişkenler & \multicolumn{2}{|c|}{ Min-max Ort $\pm S D$} \\
\hline \multirow[t]{2}{*}{ Yaş } & $18-26$ & $21,39 \pm 1,41$ \\
\hline & \multicolumn{2}{|c|}{$\mathrm{n}(\%)$} \\
\hline \multicolumn{3}{|l|}{ Cinsiyet } \\
\hline Kadın & \multicolumn{2}{|c|}{$127(\% 74,7)$} \\
\hline Erkek & \multicolumn{2}{|c|}{$43(\% 25,3)$} \\
\hline \multicolumn{3}{|l|}{ Sinıf } \\
\hline 2. sinıf & \multicolumn{2}{|c|}{$64(\% 37,6)$} \\
\hline 3. sinıf & \multicolumn{2}{|c|}{$63(\% 37,1)$} \\
\hline 4. sinıf & \multicolumn{2}{|c|}{$43(\% 25,3)$} \\
\hline \multicolumn{3}{|c|}{ Ailede meme kanseri öyküsü } \\
\hline Evet & \multicolumn{2}{|c|}{$8(\% 4,7)$} \\
\hline Hayır & \multicolumn{2}{|c|}{$162(\% 95,3)$} \\
\hline \multicolumn{3}{|c|}{$\begin{array}{l}\text { Kendi Kendine meme muayenesi } \\
\text { (KKMM) ile ilgi bilginiz var mı? }\end{array}$} \\
\hline Evet & \multicolumn{2}{|c|}{170 (\%100) } \\
\hline \multirow[t]{2}{*}{ Hayır } & \multicolumn{2}{|c|}{$0(\% 0)$} \\
\hline & Kadın & Erkek \\
\hline \multicolumn{3}{|l|}{ KKMM yapıyor musunuz? } \\
\hline Evet & $104(\% 81,9)$ & $8(18,6)$ \\
\hline Hayır & $23(18,1)$ & $35(\% 81,4)$ \\
\hline \multicolumn{3}{|l|}{ KKMM yapma sıklığınız? } \\
\hline Her ay düzenli yapıyorum & $31(\% 24,5)$ & $1(\% 2,3)$ \\
\hline Düzensiz yapıyorum & $76(\% 59,8)$ & $6(\% 14)$ \\
\hline Yapmıyorum & $20(\% 15,7)$ & $36(\% 83,7)$ \\
\hline
\end{tabular}

\begin{tabular}{ll}
\hline Anneniz düzenli olarak KKMM & \\
yapıyor mu? & $63(\% 37,0)$ \\
Evet & $55(\% 32,4)$ \\
Hayır & $52(\% 30,6)$ \\
Bilmiyorum &
\end{tabular}

Anneniz daha önce mammografi çektirdi mi?

$76(\% 44,7)$

Hayır $81(\% 47,6)$

Bilmiyorum $13(\% 7,7)$

\begin{tabular}{lc}
$\begin{array}{l}\text { Anneme daha önce meme kanseri } \\
\text { ve tarama yöntemleri hakkında }\end{array}$ \\
$\begin{array}{l}\text { bilgi verdim } \\
\text { Evet }\end{array}$ & $105(\% 61,8)$ \\
Hayır & $65(\% 38,2)$ \\
\hline
\end{tabular}

Tablo 2. Hemşirelik öğrencilerinin cinsiyet faktörüne göre KKMM yapma durumlarının karşılaştırılması

\begin{tabular}{|c|c|c|c|c|}
\hline & Kadın n (\%) & Erkek $n(\%)$ & $x^{2}$ & $p$ \\
\hline \multicolumn{5}{|c|}{$\begin{array}{l}\text { KKMM } \\
\text { yapma durumu }\end{array}$} \\
\hline Evet & $104(\% 81,9)$ & $8(\% 18,6)$ & 57237 & $n \leq 0,05 *$ \\
\hline Hayır & $23(\% 18,1)$ & $35(\% 81,4)$ & 51,231 & $p<0,05^{\prime}$ \\
\hline
\end{tabular}


Araşıırmaya katılan öğrencilerin sınıflara göre değiştirilemeyen risk faktörleri $(\mathrm{F}=5,813 ; \mathrm{p}=0,004)$, belirsiz risk faktörleri $(\mathrm{F}=11,376 ; \mathrm{p}=0,000)$, kanıtlanmamış veya tartışma1. risk faktörleri $(\mathrm{F}=4,514 ; \mathrm{p}=0,012)$ ve bilgi düzeyi toplam puanı $(\mathrm{F}=12,775 ; \mathrm{p}=0,000)$ arasında istatistiksel olarak anlamlı bir fark olduğu belirlendi. Öğrencilerin sınıflara göre erken tanı yöntemleri başlama zamanı ve sıklıkları bilgi düzeyi toplam puan ortalamaları $(F=5,105 ; \mathrm{p}=0,007)$ arasında da istatistiksel olarak anlamlı bir fark olduğu saptanmıştır (Tablo 3).

Tablo 3. Hemşirelik öğrencilerinin sınıflara göre meme kanseri risk faktörleri ve erken tanıya yönelik bilgi düzeyleri

\begin{tabular}{|c|c|c|c|}
\hline $\begin{array}{l}\text { Meme Kanseri risk } \\
\text { faktörleri }\end{array}$ & $\begin{array}{l}\text { 2. sinIf } \\
X \pm S S\end{array}$ & $\begin{array}{l}\text { 3. sinIf } \\
X \pm S S\end{array}$ & $\begin{array}{l}\text { 4. sinif } \\
X \pm S S\end{array}$ \\
\hline \multirow[t]{2}{*}{$\begin{array}{l}\text { Değiştirilemeyen Risk } \\
\text { Faktörleri }\end{array}$} & $8,75 \pm 1,33$ & $8,44 \pm 1,52$ & $7,76 \pm 1,58$ \\
\hline & & \multicolumn{2}{|c|}{$F=5,813 p=0,004^{*}$} \\
\hline
\end{tabular}

\begin{tabular}{llll}
\hline $\begin{array}{l}\text { Yaşam tarzı ile ilgili } \\
\text { risk faktörleri }\end{array}$ & $6,12 \pm 1,20$ & $5,98 \pm 1,08$ & $5,88 \pm 1,40$ \\
$\mathbf{F = 0 , 6 1 2 ~} \mathbf{p}=\mathbf{0 , 5 4 4}$ & & & \\
\hline $\begin{array}{l}\text { Belirsiz faktörler } \\
\mathrm{F}=\mathbf{1 1 , 3 7 6} \mathbf{p}=\mathbf{0 , 0 0 0 *}\end{array}$ & $2,98 \pm 0,76$ & $2,96 \pm 0,76$ & $2,31 \pm 0,80$ \\
\hline $\begin{array}{l}\text { Kanıtlanmamış veya } \\
\text { tartşmalı risk faktörleri }\end{array}$ & $\mathbf{1 , 6 7 \pm 0 , 9 0}$ & $\mathbf{1 , 9 2 \pm 0 , 9 8}$ & $\mathbf{1 , 3 7 \pm 0 , 8 4}$ \\
$\mathbf{F = 4 , 5 1 4} \mathbf{p = 0 , 0 1 2 *}$ & & & \\
\hline
\end{tabular}

$F=4,514 p=0,012 *$

Risk faktörleri bilgi

düzeyi toplam puan

$19,54 \pm 2,28 \quad 19,47 \pm 2,35 \quad 17,34 \pm 2,71$

$F=12,775 p=0,000 *$

Erken Tanı Yöntemleri

başlama zamanı ve

sıklıkları bilgi düzeyi $\quad 2,56 \pm 0,58 \quad 2,65 \pm 0,54 \quad 2,88 \pm 0,32$

toplam puan

$\mathrm{F}=5,105 \mathrm{p}=0,007$ *

X, puan ortalaması; SS, standart sapma; F, bağımsız gruplarda Anova testi; * $p<0,05$.

\section{TARTISTMA}

Çalışmadaki öğrencilerin, tamamının KKMM hakkında bilgisi olduğu, fakat sadece $\% 24,5$ 'inin düzenli olarak yaptığı saptanmıştır. Ayrıca öğrencilerin \%32,4'ünün annelerinin düzenli olarak KKMM yapmadığı, \%47,6'sının daha önce mamografi çektirmediği belirlenmiştir. Öğrencilerin erken tanılama yöntemlerine yönelik kendilerine ve ailelerine karşı tutumlarının düşük olduğu görülmüşsür. Ülkemizde KKMM erken tanı yöntemi olarak kullanılmaktadır ve kadınların kendi meme dokusunu tanıması, farklılıkları saptayabilmesi için düzenli olarak KKMM yapması önerilmektedir. ${ }^{[13,15]}$ Farklı ülkelerde yapılan çalışmalarda hemşirelik ve tıp öğrencilerinin KKMM bildiği bununla ilgili bir eğitim aldığı fakat düzenli olarak yapmadığı saptanmıştır. ${ }^{[9,14,16]}$ Aile tipi, yaşanılan bölge, gelir düzeyi, aile bireyleri arasında meme kanseri öyküsü, kişisel meme problemi öyküsü ve sağlık inancı gibi faktörlerin düzenli olarak KKMM yapma durumunu etkilediği belirtilmektedir. ${ }^{[17]}$ Yapılan çalışmaların, çalışmamızın sonuçları ile benzerlik gösterdiği görülmüştür. Öğrencilerin KKMM'ye yönelik tutumlarını geliştirmek için hemşire eğitimcilerin mevcut öğretim yöntemlerini gözden geçirmeleri gerektiği söylenebilir.

Sapountzi-Krepia ve arkadaşlarının ${ }^{[14]}$ Kıbrıs'ta yaptıkları çalışmada \%73,5'inin annesinin KKMM yapmadığı ya da bilmediğini ifade ettiği belirlenmiştir. Ülkemizde yapılan çalışmada ise, Hemşirelik öğrencilerinin annelerinin \%32,1'inin düzenli olarak KKMM yaptığı saptanmıştır. Öğrencilere KKMM yönelik yapılan eğitimlerin annelerin KKMM ve mammografi konusunda tutumlarını geliştirdiği saptanmıştır. ${ }^{[18-20]}$ Çalışmanın yapıldığı bölümde KKMM eğitimi 2. sınıfta, teorik (Power Point sunum ve video) olarak anlatılmakta ve maket üzerinde uygulamalı olarak gösterilmektedir. Daha sonra sınıftan gönüllü bir erkek ve kadın öğrencinin daha KKMM anlatması ve maket üzerinde yapması istenmektedir. Bu uygulamanın tutumları geliştirmek için yeterli olmadığı görülmüştür. Farkındalığı sağlamak, tutumları geliştirmek ve öğrenilen bilginin paylaşılmasını sağlamak için KKMM eğitiminde farklı eğitim yöntemlerinin kullanılması gerektiği düşünülmüştür.

Erkek meme kanseri tüm meme kanserlerinin \%1'inden azını oluşturan nadir bir malignitedir. ${ }^{[21]}$ Literatürde meme kanserinin erkeklerde görülme sıklığının arttığı belirtilmektedir. ${ }^{[22,23]}$ AKB'nin raporuna göre Amerika Birleşik Devletleri'nde (ABD) 2020 yılı için 2,620 erkeğe yeni meme kanseri vakası ve 520 erkekte meme kanserine bağlı ölüm vakası öngörülmüştür. ${ }^{[5]}$ Türkiye kanser istatistikleri raporuna göre erkelerde yaşa standardize edilmiş hız dağılımına göre 2014 yılında meme kanseri oranın 0,8 (Dünya Standart Nüfusu, 100,000 kişide) olduğu bildirilmiştir. ${ }^{[1]}$ Erkeklerde meme kanseri nadir görüldügü için ve jinekomasti ile karıştırılabileceğinden, tanıda gecikme yaşanabilir. Bu durum prognoz üzerinde olumsuz bir etki yaratır. ${ }^{[24,25]}$ Erkin ve Göol ${ }^{[26]}$ makalesinde Ulusal Kapsamlı Kanser Ağı (National Comprehensive Cancer Network) rehberine göre meme kanseri riski altındaki erkekler için KKMM ve klinik muayenenin önerildiği, sadece kadınların değil erkeklerinde 18 yaşından sonra ayda bir kez KKMM yapılmasını önerdiği yazılmıştır. Çalışmamızdaki erkeklerin \%81,4’ünün KKMM yapmadığı saptanmış olup, KKMM yapma durumları kadınlar ile karşılaştırıldığında istatistiksel olarak anlamlı bir fark olduğu belirlenmiştir. Yapılan çalışmalarda erkelerin meme kanserinin kadınlar 
arasında daha yaygın olduğunu ve KKMM erkekler için önemli olmadığını düşündükleri saptanmıştır. ${ }^{[27,28]}$ Erkek meme kanseri insidansında ki artış göz önüne alındığında, KKMM'nin de erkekler için önemli olduğu açıktır. Bu muayenenin gelişmekte olan ülkelerde meme kanserinin erken teşhisi için makul ve pratik bir yöntem olduğu belirtilmektedir. ${ }^{[28]} \mathrm{Bu}$ bağlamda özellikle lisans eğitimi s1rasında KKMM'nin erken teşhis için erkeklerdeki önemi belirtilmelidir.

Çalışmamızda öğrencilerin meme kanseri risk faktörleri ve erken tanı yöntemleri hakkındaki bilgi düzeylerinde sınıflar arasında istatistiksel olarak bir fark olduğu ve son sınıf puan ortalamalarının diğer sınıflara göre düşük olduğu görülmüştür. Literatür incelendiğinde hemşirelik öğrencilerinin risk faktörleri ve erken tanılamaya yönelik bilgi düzeyinin incelendiği sınırlı sayıda çalışmaya ulaşılmıştır. [10,11] Vodouhe ve ark.' nın ${ }^{[11]}$ yaptıkları çalışmada hemşirelik ve ebelik öğrencilerin yaklaşık \%16'sı en az dört meme kanseri risk faktörünü bildiği ve öğrencilerin risk faktörleri hakkında bilgisinin az olduğu saptanmıştır. Hemşirelik öğrencilerinin meme kanserine yönelik bilgi düzeyi ve KKMM düzeyi yeterliliğinin geliştirilmesi amacıyla yapılan girişimsel bir çalışmada, meme kanseri risk faktörlerine yönelik doğru cevap sayısının ve KKMM sıklığı bilgisinin Workshop öncesi az olduğu, sonrasında ise arttığı bulunmuştur. ${ }^{[10]}$

Öğrencilerin risk faktörleri ve erken tanı yöntemleri hakkındaki bilgi düzeyinin puan ortalamaları arasında sınıflar arasında farklılıklar olduğu puan ortalamasının sınıf düzeyi yükseldikçe azaldığı görülmüştür. Bu durum zamanın bilgi üzerindeki etkisini göstermektedir. Bir miktar bilginin kaybolduğu fakat kalıcı bilginin devam ettiğini görmekteyiz. Bilginin kalıcılığının sağlanması ve yıllar içerisinde azalmasını önlemek amacıyla, hemşirelik eğitimi süresince meme kanserine yönelik seminer, panel gibi eğitim faaliyetlerinin ve farkındalık etkinliklerinin düzenlenmesi önerilir. Böylece bilgileri tekrar etme ve kullanma yoluyla bilginin bellekte kalıcılığı sağlanabilir.

\section{SONUÇ Ve ÖNERILER}

Hemşirelik öğrencilerinin meme kanseri konusunda farkındalığının sağlanması, yeterli bilgi düzeyi ile mezun olmalarını sağlayabilmek için lisans eğitim süresince meme kanserine yönelik panel, seminer gibi eğitim faaliyetlerinin ve farkındalık etkinliklerin planlanması önerilir. Ayrıca hemşire eğitimcilerin mevcut eğitim yöntemlerini gözden geçirmesi, öğrencilerin tutumlarının geliştirilmesine katk1 sağlayacak interaktif eğitim yöntemlerini kullanmaları önerilir.

\section{Etik Kurul Onayı}

Çalışma, Çankııı Karatekin Üniversitesi Girişimsel olmayan Etik kurulu tarafından onaylandı. (onay tarihi ve sayısı: 21.04.2020/165).

Hakem Değerlendirmesi

Dış bağımsız.

Çıkar Çatışması

Yazar çıkar ilişkisi olmadığını beyan etmişlerdir.

Finansal Destek

Herhangi bir mali destek alınmamıştır.

Ethics Committee Approval

The study was approved by the Çankırı Karatekin University non-interventional Ethics Committee. (date and number of approval: 21.04.2020/165).

\section{Peer-review}

Externally peer-reviewed.

Conflict of Interest

No conflict of interest was declared by the author.

Financial Disclosure

No financial support has been received.

\section{KAYNAKLAR}

1. T. C. Sağlık Bakanlığı. Türkiye Kanser İstatistikleri 2017. Ankara; 2017. https://hsgm.saglik.gov.tr/tr/kanser-istatistikleri/ yillar/2017-turkiye-kanser-i-statistikleri.html

2. International Agency for Research on Cancer. Globocan 2020. https://gco.iarc.fr/today/data/factsheets/cancers/20-Breast-factsheet.pdf

3. Powe BD, Underwood S, Canales M, Finnie R. Perceptions about breast cancer among college students: implications for nursing education. J Nurs Educ 2005;44:257-65. [CrossRef]

4. Karayurt Ö, Coşkun A, Cerit K. Hemşirelerin meme kanseri ve kendi kendine meme muayenesine ilişkin inançları ve uygulama durumu. J Breast Health 2008;4:15-20. http://cms.galenos.com. tr/Uploads/Article_42668/ejbh-4-15-En.pdf

5. American Cancer Society. Breast Cancer; 2020. https://www. cancer.org/cancer/breast-cancer.html

6. Gök Özer F, Taşcı Beydağ KD, Özbay C. Hemşirelik öğrencilerinin meme kanseri hakkındaki bilgileri ve meme muayenesini uygulama durumları. Pamukkale Tip Derg 2009;2:15-9. https://www. journalagent.com/ptd/pdfs/PTD_2_1_15_19.pdf

7. Beydağ KD, Yürügen B. The effect of breast self-examination (BSE) education given to midwifery students on their knowledge and attitudes. Asian Pac J Cancer Prev 2010;11:1761-4. http://journal. waocp.org/article_25446_bd74ae69a80b9a6f243e8bb45ddff1 14 . pdf

8. İlhan N, Çöl AG, Tanboğa E, Şengül A, Batmaz M. Sağlıkla ilgili bölümlerde okuyan üniversite öğrencilerinin meme kanserinin erken tanısına yönelik davranışları. J Breast Health 2014;10:14753. [CrossRef]

9. Höbek Akarsu R, Yüzer Alsaç S. Hemşirelik öğrencilerinin kendi kendine meme muayenesini bilme ve uygulama durumlarının belirlenmesi. Bozok Tip Derg 2019;9:115-21. [CrossRef]

10. Yousuf SA. Breast cancer awareness among saudi nursing students. JKAU Med Sci 2010;17:67-78. [CrossRef]

11. Vodouhe MV, Lokossou MSHS, Salifou K, Ogoudjobi OM, Sidi IR, Hounkponou FM, et al. Knowledge of risk factors and early detection signs of breast cancer by students at nursing and midwifery training institute (IFSIO) in Parakou (Benin). J Women's Health Care 2018;7:2-6. [CrossRef]

12. Esen ES, Gelmez Taş B, Öztürk GZ, Toprak D. 18 yaş ve üzeri kadınlarda meme kanseri risk düzeyinin belirlenmesi. Türk Aile Hekim Derg 2020;24:32-40. [CrossRef] 
13. T. C. Sağlık Bakanlığı, Halk Sağlığı Genel Müdürlüğü, Kanser Dairesi Başkanlığı. Meme Kanseri; 2017. https://hsgm.saglik.gov. tr/tr/kanser-turleri/kanser-turleri/meme-kanseri.html

14. Sapountzi-Krepia D, Rekleiti M, Lavdanit M, Psychogiou M, Chaliou M, Xenofontos M, Savva M. Evaluating female nursing students' knowledge and attitudes regarding breast selfexamination. Health Care Women Int 2017;38:786-95. [CrossRef]

15. Akyolcu N, Altun Uğraş G. Kendi kendine meme muayenesi: erken tanıda ne kadar önemli? J Breast Health 2011;7:10-4. http://cms. galenos.com.tr/Uploads/Article_42445/ejbh-7-10-En.pdf

16. Ansari AB, Shahzad N, Bota R, Ahmed M, Khalid B, Aziz A, Yaseen M. Medical students' knowledge and attitude towards breast cancer risk factors and early detection practices. Austin Med Sci 2018;3:1-3.

17. Kara B, Acikel CH. Health beliefs and breast self-examination in a sample of Turkishnursing students and their mothers. J Clin Nurs 2008;18:1412-21. [CrossRef]

18. Abasi E, Tahmasebi H, Zafari M, Tofigi M, Hasani S. The impact of female students' breast self-examination training on their mothers' awareness. J Midwifery Reprod Health 2018;6:1454-61. [CrossRef]

19. Akkaş Gürsoy A, Yılmaz F, Nural N, Kahriman İ, Yiğitbaş Ç, Erdöl H, et al. A Different approach to breast self-examination education. Cancer Nurs 2009;32:127-34. [CrossRef]
20. Sun Kang H, Hyun M-S, Kim M. The effects of daughter's breast health education on mother's breast cancer screening attitude. J Korean Acad Community Health Nurs 2010;21:273-81. [CrossRef]

21. Yousef AJA. Male breast cancer: epidemiology and risk factors. Semin Oncol 2017;44:267-72. [CrossRef]

22. Yalçıntaş Arslan Ü, Öksüzoğlu B, Özdemir N, Aksoy S, Alkış N, Gök A, et al. Outcome of non-metastatic male breast cancer:118 patients. Med Oncol 2012;29:554-60. [CrossRef]

23. Johansen Taber KA, Morisy LR, Osbahr AJ, Dickinson BD. Male breast cancer: risk factors, diagnosis, and management (Review). Oncol Rep 2010;24:1115-20. [CrossRef]

24. Anderson WF, Jatoi I, Tse J, Rosenberg PS. Male breast cancer: a population-based comparison with female breast cancer. J Clin Oncol 2010;28:232-9. [CrossRef]

25. Ottini L, Palli D, Rizzo S, Federico M, Bazan V, Russo A. Male breast cancer. Crit Rev Oncol Hematol 2010;73:141-55. [CrossRef]

26. Erkin Ö, Göl İ. Validity and Reliability of Turkish Male Breast Self-Examination Instrument. Eur J Breast Health 2018;14:121-6. [CrossRef]

27. Thomas E. Original Research: Men's awareness and knowledge of male breast cancer. Am J Nurs 2010;110:32-7. [CrossRef]

28. Al-Naggar RA, Al-Naggar DH. Perceptions and opinions about male breast cancer and male breast self-examination: a qualitative study. Asian Pac J Cancer Prev 2012;13:243-6. [CrossRef] 